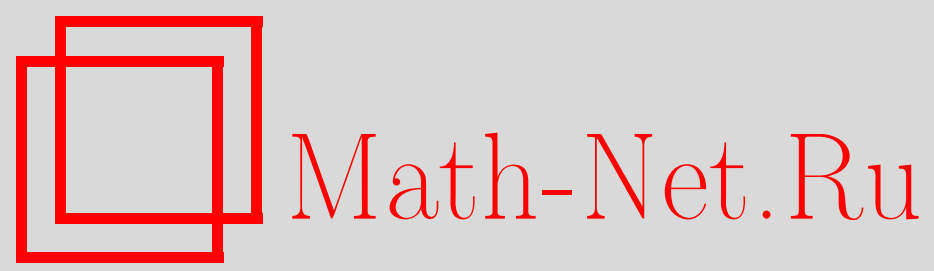

П. Е. Кичаев, Влияние предварительного неупругого деформирования на выносливость деталей с концентратором напряжений, Вестн. Сам. гос. техн. ун-та. Сер. Физ.-мат. науки, 2003, выпуск 19, 173-176

DOI: https://doi.org/10.14498/vsgtu163

Использование Общероссийского математического портала Math-Net.Ru подразумевает, что вы прочитали и согласны с пользовательским соглашением

http://www.mathnet.ru/rus/agreement

Параметры загрузки:

IP : 3.85 .7 .115

26 апреля 2023 г., 08:28:17 


\section{I.E. Кичаев}

\section{ВЛИЯНИЕ ПРЕДВАРИТЕЛЬНОГО НЕУПРУГОГО ДЕФОРМИРОВАНИЯ НА ВЫНОСЛИВОСТЬ ДЕТАЛЕЙ С КОНЦЕНТРАТОРОМ НАПРЯЖЕНИЙ}

Проведена экспериментальная оченка влияния предварительного неупругого деформирования в режиме пластики и ползучести на последующую выносливость сплавов ЭП- 742 и ВТЗ-1.

Надежность и долговечность машин, как правило, зависит от выносливости их отдельных деталей и элементов. Значительный резерв прочности и долговечности заключен в предварительном неупругом деформировании различных концентраторов напряжений, имеющихся на узлах и деталях (что создает благоприятное распределение остаточных напряжений в поверхностном слое материала). Существует несколько методов технологического повышения усталостной прочности, таких, как термомеханическое упрочнение, создание различного рода поверхностных покрытий, обкатка. Все названные методы затрагивают только поверхностные слои, меняя их структуру или создавая в них остаточные напряжения желаемого знака, обычно сжимающие. При этом «подкорковые слои» остаются или незатронутыми, или в них возникают нежелательные растягивающие напряжения. Кроме того, подобное деформирование ведет к накоплению повреждений в материале, что нежелательно. В силу сказанного температурносиловой и скоростной режимы нагружения рекомендуется подбирать таким образом, чтобы величина накопленных повреждений была минимальной.

В последнее время предпринимаются попытки наведения остаточных напряжений в зонах их концентрации путем предварительного деформирования в режиме ползучести. В этом случае возможно получение эпюр остаточных напряжений желаемого знака, более приближенных к оптимальным [1].

Построение уравнений состояния и определение характеристик деформирования материалов. В настоящей работе развивается ранее предложенный энергетический подход к описанию деформирования и разрушения материалов $[2,3]$. Определяющие уравнения построены при введении гипотезы, согласно которой параметр поврежденности в материале полагается пропорциональным линейной комбинации работ истинного напряжения на деформации пластичности и ползучести.

Основной вид определяющих соотношений имеет вид

$$
\begin{aligned}
& \varepsilon=e+e^{\mathrm{p}}+p ; \\
& \&=\sigma / \mathrm{E}, \&=\wp S^{\prime}(\sigma) \propto ; \\
& p=u+v+w \text {; } \\
& u(t)=\sum_{k=1}^{s} u_{k}(t), \alpha_{k}^{\alpha}(t)=\lambda_{k}\left[a_{k}\left(\sigma / \sigma_{*}\right)^{n}(t)-U_{k}(t)\right] ; \\
& \begin{array}{l}
v(t)=\sum_{k=1}^{s} v_{k}(t), \alpha_{k}^{\alpha}(t)=\left\{\begin{array}{l}
\lambda_{k}\left[b_{k}\left(\sigma / \sigma_{*}\right)^{n}(t)-V_{k}(t)\right], b_{k}\left(\sigma / \sigma_{*}\right)^{n}(t)>V_{K}(t), \\
O, b_{k}\left(\sigma / \sigma_{*}\right)^{n}(t) \leq V_{k}(t) ;
\end{array}\right\} \\
\delta(t)=C\left(\sigma / \sigma_{*}\right)^{m}(t) ;
\end{array} \\
& \sigma=\sigma_{0}(1+\omega) ; \\
& \alpha=\& y \sigma+\alpha \sigma \sigma,
\end{aligned}
$$

где $\varepsilon$ - полная деформация; $e$ и $e^{p}$ - упругая и пластическая деформации; $p$ - деформация ползучести; $u, v, w$ - соответственно вязкоупругая, вязкопластическая и вязкая составляющие $p$; $\sigma_{0}$ и $\sigma$ - номинальное и истинное напряжение соответственно; $\omega$ - параметр поврежденности, который полагается пропорциональным линейной комбинации работ истинного напряжения на деформации ползучести и на пластической деформации; $E$ - модуль Юнга; $\lambda_{k}, \alpha_{k}, d_{k}, C, m, n, \sigma_{*}$ реологические константы материала, при помощи которых описывается первая и вторая стадии ползучести и обратимая часть деформации ползучести; $\gamma$ и $\alpha$ - параметры материала, контролирующие процессы разупрочнения материала. 


$$
\gamma=\gamma_{1}\left(e^{p}\right)^{m_{2}}, a=a_{1}\left(\sigma_{0}\right)^{m_{1}} .
$$
шение

Для прогнозирования момента разрушения $t=t^{*}$ в качестве критерия предлагается соотно-

$$
\int_{0}^{t_{*}} \frac{\sigma(t) d e^{p}(t)}{A_{*}^{p}}+\int_{0}^{t *} \frac{\sigma(t) d P(t)}{A_{*}^{C}}=1
$$

где $\mathrm{A}_{\mathrm{p}}{ }^{*}$ и $\mathrm{A}_{\mathrm{c}}{ }^{*}$ - соответственно критические величины работ разрушения истинного напряжения на пластической деформации и деформации ползучести, которые при $\mathrm{T}=\mathrm{const}$ являются константами материала.

Таким образом, соотношения (1)-(5) позволяют вычислить необратимые деформации и поврежденность материала при квазистатическом нагружении.

В качестве испытуемых материалов выбраны: титановый сплав ВТ3-1, применяемый для изготовления проушин рычагов взлетно-посадочных устройств самолетов; сплав ЭП 742, из которого изготавливаются диски и лопатки газовых турбин. Температуры испытаний, соответствующие рабочим, составляли 20 и $450^{\circ} \mathrm{C}$ для сплава ВТ3-1 и $750^{\circ} \mathrm{C}$ для ЭП - 742. Испытывались круглые образцы с концентратором и без него. Геометрия захватов образцов унифицирована таким образом, чтобы обеспечить возможность их испытания при квазистатическом нагружении на установке Zst 3/3 и при циклическом нагружении на усталостной машине УВМ. Для определения параметров модели проведены следующие базовые испытания гладких, без концентратора, образцов по следующим программам.

1. Механические испытания при скорости активного захвата 20 мм/мин для получения кривой мгновенного растяжения. По кривой определяются механические характеристики и параметры пластичности материалов при выбранных температурах испытаний.

2. Испытания на ползучесть при трех уровнях начального напряжения, по результатам которых вычисляются параметры ползучести и длительной прочности.

3. Испытания на усталость при симметричном цикле для получения кривой Веллера и, соответственно, расчета параметров выносливости материалов. Каждое испытание повторялось, и при определении расчетных параметров опытные данные усреднялись. Кривые растяжения сплава ВТ3-1 и сплава ЭП - 742 представлены на рис. 1. Кривые ползучести изображены на рис. 2 и 3.

Кривые Веллера, вычисленные с вероятностью 0,9 , показаны на рис. 4 и 5 . Рассчитанные параметры разработанной модели приведены в табл. 1 и 2.

Кривая Веллера описывается уравнением $N=\mathrm{Q} \sigma_{\mathrm{a}}^{-\mathrm{q}}$, где для сплава ВТ3-1 получено: $Q=8,72.10^{369}, q=133$; сплава ЭП -742 $Q=0,39.10^{16}, q=13,6$; величина $\sigma_{a}$ амплитудное значение циклической составляющей.

4. Экспериментальная оценка влияния предварительного неупругого деформирования на последующую выносливость образцов с концентраторами напряжений.

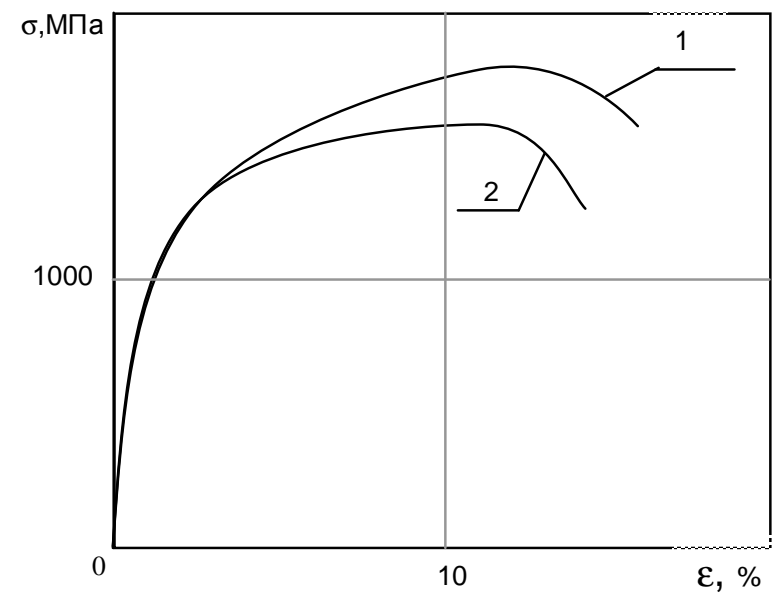

Р и с. 1 Кривые мгновенного деформирования сплавов ЭП -742 (Т=750 $\left.{ }^{\circ} \mathrm{C}\right)(1)$ и ВТ3-1 $\left(\mathrm{T}=450^{\circ} \mathrm{C}\right)(2)$

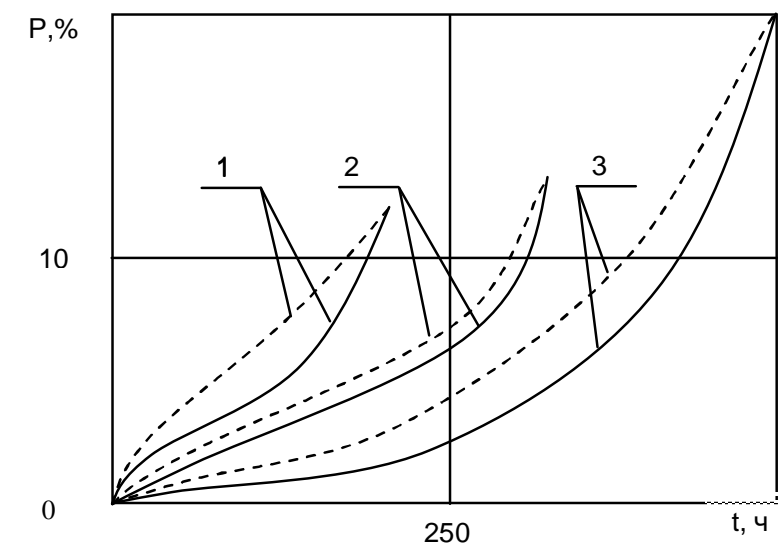

Р и с. 2. Расчетные (пунктиром) и экспериментальные (сплошные) кривые ползучести сплава ВТ3-1 ( $\left.\mathrm{T}=450^{\circ} \mathrm{C}\right): 1$ - $700 \mathrm{MПа;} 2$ - $600 \mathrm{MПа;} 3$ $500 \mathrm{MПа}$ 
На втором этапе проводились испытания образцов с круглыми выкружками. При выбранной геометрии образцов максимальный коэффициент концентрации напряжений К равен 2,2 [4]. Под коэффициентом концентрации напряжений понимается отношение величины напряжения в точке при наличии концентратора к напряжению в этой точке при отсутствии концентратора. В испытуемых образцах наводилась остаточная деформация 0,25 и 0,5 ресурса пластичности материала $\mathrm{P}^{*}$ пластичностью и ползучестью, после чего они испытывались на выносливость при симметричном цикле для напряжений.

Результаты сравнивали с результатами испытания образцов в исходном состоянии. Экспериментальные данные приведены в табл. 3, а кривые Веллера для образцов с концентратором напряжений изображены на рис. 4 и 5. На основании полученных данных можно сделать следующие выводы.

1. Наведение остаточных деформаций в режиме ползучести и в режиме пластичности повышает предел выносливости.

2. Для сплава ВТ3-1 повышение предела выносливости деформированием в режиме ползучести по отношению к пластическому деформированию незначительно, а для сплава ЭП - 742 повышение предела выносливости деформированием в режиме ползучести по отношению к пластическому деформированию превышает в 4 раза.

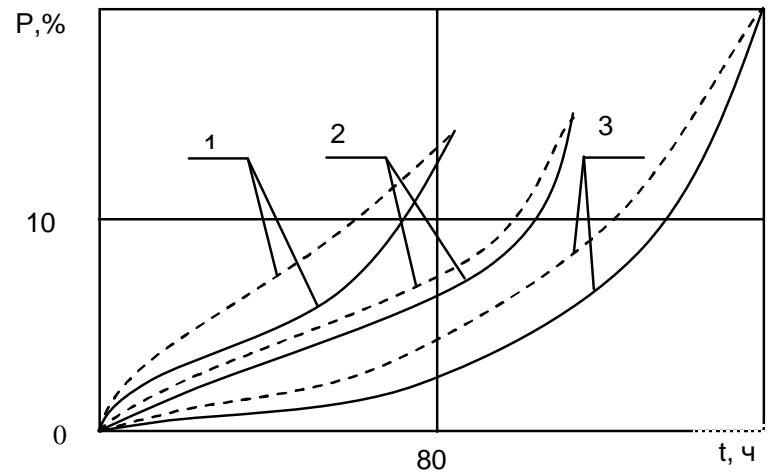

Р и с. 3. Расчетные (пунктиром) и экспериментальные (сплошные) кривые ползучести сплава ЭП 742 $\left(\mathrm{T}=750^{\circ} \mathrm{C}\right)$ :

1 - 480 МПа; 2 - 580 МПа; 3 - 700 МПа

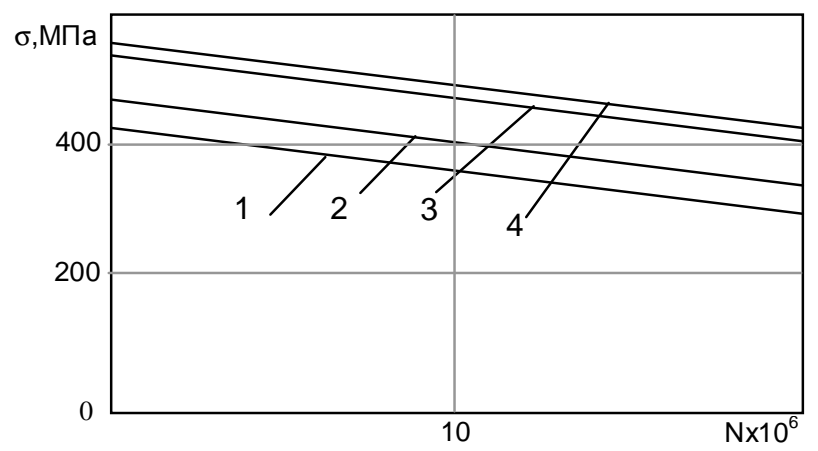

Р и с. 4. Кривые выносливости сплава ВТ3-1 $\left(\mathrm{T}=450^{\circ} \mathrm{C}\right)$ :

1 - исходная; 2- пластическая деформация 0,25Р*; 3 - пластическая деформация $0,5 \mathrm{P} *$; 4 - деформация ползучести $2 \%$

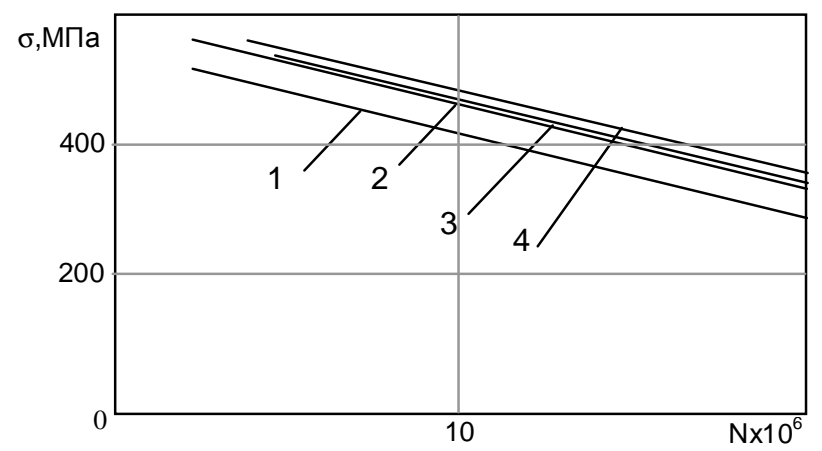

Р и с. 5. Кривые выносливости сплава ЭП - 742 $\left(\mathrm{T}=750^{\circ} \mathrm{C}\right)$ :

1 - исходная; 2- пластическая деформация 0,25P*; 3 - пластическая деформация $0,5 \mathrm{P} *$; 4- деформация ползучести $2 \%$

Т а б л и ц а 1

Значения параметров кривой мгновенного деформирования

\begin{tabular}{|c|c|c|c|c|c|c|c|c|}
\hline Материал & $\mathrm{T},{ }^{0} \mathrm{C}$ & $\sigma_{\text {пр, }}, \mathrm{MПа}$ & $\begin{array}{l}\text { E.10-6, } \\
\text { МПа }\end{array}$ & $\mathrm{g} \mathrm{MПа}^{-\mathrm{h}}$ & $h$ & $\gamma_{1}, \mathrm{M \Pi a}^{-1}$ & $m_{2}$ & $\begin{array}{c}\mathrm{A}_{\mathrm{p}}{ }^{3} \\
\text { МДж/M }\end{array}$ \\
\hline \multirow{2}{*}{ ЭП - 742} & 20 & 880 & 2,25 & $1,311 \cdot 10^{-6}$ & 1,776 & $1,88 \cdot 10^{-3}$ & 0 & 281,2 \\
\hline & 750 & 620 & 1,943 & $0,492 \cdot 10^{-6}$ & 1,943 & $1,655 \cdot 10^{-3}$ & 0 & 183,3 \\
\hline \multirow{2}{*}{ BT3-1 } & 20 & 970 & 1,15 & $0,54 \cdot 10^{-6}$ & 2,4 & $5 \cdot 10^{-8}$ & 11 & 80,7 \\
\hline & 450 & 773,2 & 0,669 & $32,3 \cdot 10^{-6}$ & 1,524 & 11,0 & 2,95 & 66,7 \\
\hline
\end{tabular}


Значения параметров ползучести

\begin{tabular}{|c|c|c|c|c|c|c|c|c|c|c|c|c|}
\hline $\begin{array}{c}\text { Мате- } \\
\text { риал }\end{array}$ & $\begin{array}{c}\mathrm{T}, \\
{ }^{0} \mathrm{C}\end{array}$ & $\begin{array}{c}\sigma_{*} \\
\mathrm{MПа}\end{array}$ & $S$ & $\lambda_{\mathrm{k}}$ & $a_{\mathrm{k}}$ & $b_{\mathrm{k}}$ & $c$ & $n$ & $m$ & $\begin{array}{c}\alpha_{1} \\
\mathrm{MПa}^{(-} \\
\mathrm{m}^{(-1)}\end{array}$ & $\begin{array}{c}\mathrm{A}_{\mathrm{c}}^{*}, \\
m_{1}\end{array}$ & $\begin{array}{c}\mathrm{M}^{*} / \\
\mathrm{M}^{3}\end{array}$ \\
\hline ЭП -742 & 750 & 500 & 1 & 0,2 & $6,55 \cdot 10^{-4}$ & $4,9 \cdot 10^{-3}$ & $4,15 \cdot 10^{-4}$ & 3,76 & 8,9 & $1,47 \cdot 10^{5}$ & $-3,3$ & 88,77 \\
\hline ВТ3-1 & 450 & 500 & 1 & 0,2 & 0 & $4,6 \cdot 10^{-3}$ & $2,07 \cdot 10^{-4}$ & 1,86 & 9,5 & $7,42 \cdot 10^{5}$ & $-2,7$ & 12,7 \\
\hline
\end{tabular}

Т а б ли ц а 3

Результаты сравнительных испытаний на усталость образцов с концентратором

\begin{tabular}{|c|c|c|c|c|}
\hline \multicolumn{2}{|c|}{} & $\begin{array}{c}\text { Пластика } \\
P=0,25 \mathrm{P}^{*}\end{array}$ & $\begin{array}{c}\text { Пластика } \\
P=0,5 \mathrm{P}^{*}\end{array}$ & $\begin{array}{c}\text { Ползучесть } \\
P=0,25^{*}\end{array}$ \\
\hline \multirow{2}{*}{$\begin{array}{c}\text { Увеличение пре- } \\
\begin{array}{c}\text { дела выносливо- } \\
\text { сти, \% }\end{array}\end{array}$} & ВТ3-1 & 15,6 & 7,12 & 18,3 \\
\cline { 2 - 5 } & ЭП742 & 19,4 & 8,69 & 4,92 \\
\hline
\end{tabular}

БИБЛИОГРАФИЧЕСКИЙ СПИСОК

1. Методы расчета на прочность изделий машиностроения при их обработке давлением в режиме ползучести и сверхпластичности: Метод. рекомендации. Новосибирск: Госстандарт, 1989. 67 с.

2. Радченко В.П. Энергетический вариант одноосной теории ползучести и длительной прочности // ПМТФ. 1991. N4. C.172-179.

3. Радченко В.П., Кичаев Е.К. Энергетический вариант определяющих уравнений и критерий разрушения при виброползучести материалов // Актуальные проблемы прочности: Мат. XXVIII. респ. сем. Вологда, 1992. С.25-26.

4. Трощенко В.T. Усталость и неупругость металлов. Киев: Наукова думка, 1971. 420 с. 